\title{
Evaluating the Snow Crystal Size Distribution and Density Assumptions within a Single-Moment Microphysics Scheme
}

\author{
Andrew L. Molthan And Walter A. Petersen \\ NASA Marshall Space Flight Center, Huntsville, Alabama \\ STEPHEN W. NESBITT \\ Department of Atmospheric Sciences, University of Illinois at Urbana-Champaign, Urbana, Illinois \\ DAVID HUDAK \\ Environment Canada, King City, Ontario, Canada
}

(Manuscript received 4 May 2010, in final form 29 June 2010)

\begin{abstract}
The Canadian CloudSat/Cloud-Aerosol Lidar and Infrared Pathfinder Satellite Observations (CALIPSO) Validation Project (C3VP) was a field campaign designed to obtain aircraft, surface, and radar observations of clouds and precipitation in support of improving the simulation of snowfall and cold season precipitation, their microphysical processes represented within forecast models, and radiative properties relevant to remotely sensed retrievals. During the campaign, a midlatitude cyclone tracked along the U.S.-Canadian border on 22 January 2007, producing an extensive area of snowfall. Observations of ice crystals from this event are used to evaluate the assumptions and physical relationships for the snow category within the Goddard six-class, single-moment microphysics scheme, as implemented within the Weather Research and Forecasting (WRF) model.

The WRF model forecast generally reproduced the precipitation and cloud structures sampled by radars and aircraft, permitting a comparison between C3VP observations and model snowfall characteristics. Key snowfall assumptions in the Goddard scheme are an exponential size distribution with fixed intercept and effective bulk density, and the relationship between crystal diameter and terminal velocity. Fixed values for the size distribution intercept and density did not represent the vertical variability of naturally occurring populations of aggregates, and the current diameter and fall speed relationship underestimated terminal velocities for all sizes of crystals.
\end{abstract}

\section{Introduction}

As computational resources continue to grow, weather forecast models are transitioning to the use of parameterizations that predict the evolution of hydrometeors and their microphysical processes. Currently, the National Centers for Environmental Prediction (NCEP) utilize the Nonhydrostatic Mesoscale Model (NMM) version of the Weather Research and Forecasting (WRF) model (Janjić 2001, 2003) as one of their forecast tools for weather prediction throughout North America. In support of forecast

Corresponding author address: Andrew L. Molthan, NASA Marshall Space Flight Center, 320 Sparkman Dr., Huntsville, AL 35805 .

E-mail: andrew.molthan@nasa.gov model research and test bed efforts, high-resolution WRF model forecasts have been produced, focusing on forecasts of severe convection (Kain et al. 2003) and the prediction of winter storms (Bernardet et al. 2008). Numerous microphysics schemes are available within the WRF model as of version 3.2, ranging from early single-moment schemes designed for the prediction of warm rain processes (Kessler 1969) to schemes that include a single-moment characterization of varying numbers of ice classes (Lin et al. 1983; Hong et al. 2004; W.-K. Tao et al. 2008, personal communication; Thompson et al.2008), and the inclusion of two double-moment schemes to improve the representation of particle number concentrations (Milbrandt and Yau 2005; Morrison et al. 2009). Many of these schemes incorporate relationships based upon observations obtained during aircraft field campaigns, 
relating size distributions and other properties to ambient temperature (Hong et al. 2004; Thompson et al. 2008).

Common to all schemes are assumptions or parameterizations to characterize the properties of hydrometeor size distributions, their bulk densities, and their terminal fall speeds. Lin et al. (1983) and Rutledge and Hobbs (1984) developed equations for the prediction of up to six mixing ratios $\left(q_{x}\right)$ representing water mass: vapor, cloud ice, cloud water, snow $\left(q_{s}\right)$, rain, and graupel or hail. Although cloud water droplets and cloud ice crystals were assumed to be monodisperse, the rain, snow, and graupel categories were prescribed an exponential size distribution:

$$
N_{x}(D)=N_{\mathrm{ox}} e^{-\lambda_{x} D},
$$

where the number concentration of a hydrometeor with diameter $D, N_{x}(D)$, is determined as a function of the size distribution intercept $N_{\text {ox }}$ and slope parameter $\lambda_{x}$.

The total mass within the particle size distribution depends upon the relationship between mass and diameter. Herein, discussion will emphasize various assumptions related to the snow category. Locatelli and Hobbs (1974) determined relationships between crystal diameter and mass in a power-law form:

$$
M(D)=a_{m} D^{b_{m}}
$$

where values of $b_{m}$ averaged around 2 for unrimed aggregates, suggesting that mass was related to the crosssectional area. Rimed crystals tended to have a greater amount of mass within the same cross-sectional area, resulting in larger values of $a_{m}$ for relatively small changes in $b_{m}$. Populations of crystals can be characterized by their effective bulk density, or the ratio of the total particle mass to the total volume of all equivalent diameter spheres. The effective bulk density of a crystal population has been related to the slope parameter of their best-fit, exponential size distribution (Heymsfield et al. 2004). Lin et al. (1983) represented snow crystals by spheres, where the mass of a single particle in (2) is the product of $\rho_{s}$ and its spherical volume, or $a_{m}=(\pi / 6) \rho_{s}$ and $b_{m}=3$. By integrating the product of (1) and (2) to obtain the total mass within the population $\left(q_{s} \rho_{a}\right)$, the slope of the distribution $\lambda_{s}$ can be isolated in terms of the distribution intercept $N_{\text {os }}$ and a constant effective bulk density:

$$
\lambda_{s}=\left(\frac{N_{\mathrm{os}} \pi \rho_{s}}{q_{s} \rho_{a}}\right)^{1 / 4} .
$$

When $N_{\text {os }}$ and $\rho_{s}$ are fixed, variability in $\lambda_{s}$ will be determined only by changes in the snow content. In the exponential size distribution, the arithmetic mean size is equal to $\lambda_{s}^{-1}$, implying that increases (decreases) in mean particle size will be limited to regions where snow content increases (decreases).

The fall speeds of individual crystals are determined by a power-law relationship between terminal velocity and diameter, following Locatelli and Hobbs (1974), with a correction factor that allows for an increase in fall speed as air density decreases (Heymsfield 1973):

$$
V(D)=a_{v} D^{b_{v}}\left(\frac{\rho_{o}}{\rho}\right)^{1 / 2},
$$

where $\rho_{o}$ represents the air density at the surface, and $\rho$ the local air density surrounding the falling crystals. Values of $a_{v}$ and $b_{v}$ vary by crystal habit and degree of riming (Locatelli and Hobbs 1974). The integrated product of (1), (2), and (4) determines the mass flux or precipitation rate. In addition, these relationships determine the size distribution and fall speeds required for calculations of accretion rates, since accretion depends upon the volume swept out by falling crystals and their consumption of other hydrometeors.

The Goddard six-class, single-moment microphysics scheme incorporates many of the equations developed by Lin et al. (1983) and Rutledge and Hobbs (1984), and continues the use of a fixed, exponential size distribution intercept and effective bulk density. Additional benefits of the Goddard scheme include an improved representation of the Bergeron process, noniterative methods for saturation adjustment, an order of operations that executes all microphysical processes with the same temperature profile, and modified snow and graupel production processes to reduce high density particles within thunderstorm anvils (Tao et al. 2003; Lang et al. 2007; W.-K. Tao et al. 2008, personal communication).

The Goddard scheme can provide additional value by generating a suite of simulated cloud profiles useful in the development of satellite-based retrievals of cloud properties and precipitation rate. Profiles of ice and liquid water content, combined with accurate size distributions and fall speeds, will allow for the simulation of passive microwave brightness temperatures and radar reflectivity from current sensors (Matsui et al. 2009) and future instruments in the National Aeronautics and Space Administration (NASA) Global Precipitation Measurement (GPM) mission. Accurate estimation of ice crystal properties is key, given the diversity in microwave scattering among naturally occurring crystal habits (Liu 2004, 2008a). Water vapor and small cloud droplets or ice crystals must also be represented because although they may not contribute to precipitation, they remain a factor in estimating signal attenuation and provide additional scattering to remote sensors. 
Herein, we present a synthesis of observations of a widespread snowfall event on 22 January 2007, observed during the Canadian CloudSat/Cloud-Aerosol Lidar and Infrared Pathfinder Satellite Observations (CALIPSO) Validation Project (C3VP). Field campaigns such as C3VP provide important data required to evaluate the assumptions made within the Goddard scheme by measuring particle size distributions and hydrometeor mass content via surface and aircraft instruments. Aircraft crystal probe imagery, measurements of ice water content, and atmospheric state parameters can be compared against Goddard scheme output to examine the consistency between observed and modeled characteristics of ice microphysics for this particular event.

\section{The Canadian CloudSat/CALIPSO Validation Project}

The C3VP campaign was a multinational collaboration between the CloudSat/CALIPSO and NASA GPM communities to provide a suite of observations necessary for the evaluation and improvement of high-resolution forecast models, which predict the hydrometeor mass content and precipitation rates of multiple liquid or ice phase categories (Hudak et al. 2006; Petersen et al. 2007). Snowfall and cold season precipitation were emphasized to assist with the development of satellite retrievals for current and future remote sensors. In this application, high resolution refers to a horizontal grid spacing $(1 \mathrm{~km})$ comparable to the along-track resolution $(1.7 \mathrm{~km})$ of the 94-GHz CloudSat radar. CloudSat was designed for sensitivity to small ice crystals and the capability of detecting snowfall from space (Liu 2008b). Attenuation of the radar signal by ice is much less than attenuation by cloud water or rainfall when water content is minimal (Stephens et al. 2002). During C3VP, the operational, C-band, dualpolarimetric radar at King City, Ontario, Canada, was used in conjunction with a vertically pointing, groundbased cloud radar to validate CloudSat reflectivity products (Hudak et al. 2008), while also providing additional detail about cloud microphysical processes. Other relevant satellite sensors include the $89-\mathrm{GHz}$ channel of the Advanced Microwave Scanning Radiometer for Earth Observing System (AMSR-E) aboard the NASA Aqua satellite and the Advanced Microwave Sounding Unit-B (AMSU-B) aboard National Oceanic and Atmospheric Administration (NOAA) polar-orbiting satellites. Each remote sensor samples clouds and precipitation over the C3VP operational domain.

Radar and satellite observations of precipitation were supplemented by surface optical disdrometers, measurement of crystal terminal velocities, and a time series of temperature and liquid equivalent precipitation from an

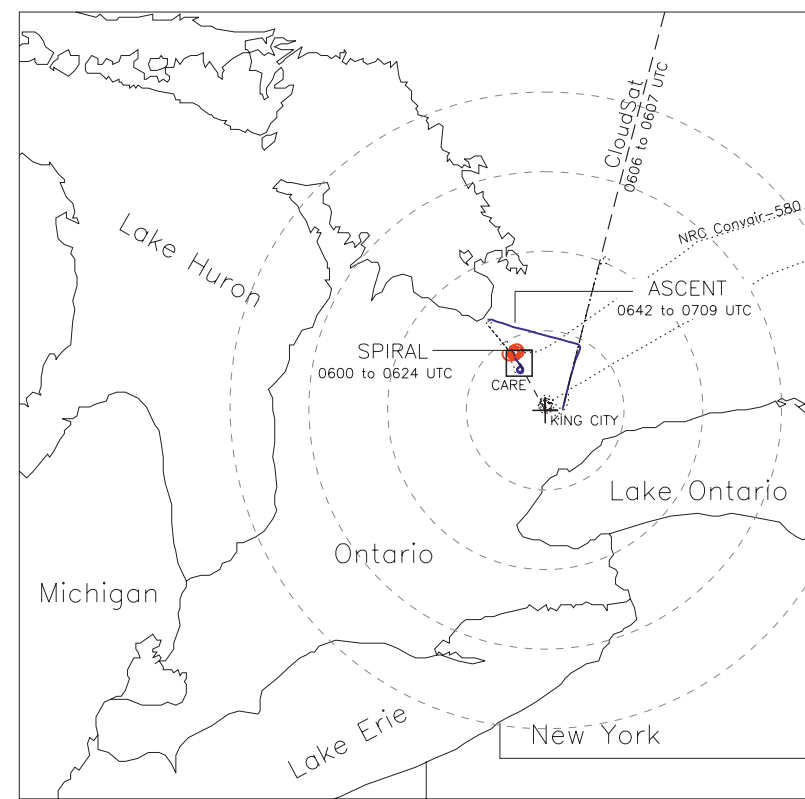

FIG. 1. Overview of the C3VP operational domain and datasets used in this study. The crosshair indicates the location of the dualpolarimetric radar at King City, Ontario, with range rings in 50-km increments. The heavy dashed line oriented southeast to northwest is along the $331^{\circ}$ azimuth of range-height scans obtained from the King City radar. Portions of the aircraft flight track referred to as the spiral and ascent are color coded and referenced in subsequent figures and the remainder of the text.

experimental U.S. Climate Reference Network (USCRN) site located near Egberg, Ontario, Canada. Campaign deployments were managed at the Canadian Centre for Atmospheric Research Experiments (CARE) site in southeastern Ontario, and included the deployment of an instrumented Convair-580 aircraft provided by $\mathrm{Na}-$ tional Research Council Canada (NRC Convair-580), capable of measuring snow crystal size distributions, ice water content, and atmospheric state data from wing mounted probes (Fig. 1).

\section{a. Development of precipitation on 22 January 2007}

Snowfall during the 22 January 2007 event was generated by a midlatitude cyclone traveling along the U.S.-Canadian border between 0000 and 1200 UTC. The cyclone produced a broad area of snowfall across southern Ontario, associated with synoptic-scale ascent to the north of a warm frontal boundary. Precipitation and cloud cover were sampled by surface instrumentation, upper-air soundings, and aircraft probes, with structures remotely sensed by the King City and CloudSat radars. A liquid equivalent accumulation of $2.8 \mathrm{~mm}$ was measured at the USCRN site between 0200 and 0800 UTC, while surface temperatures during the period were nearly steady at $-9^{\circ} \mathrm{C}$ (Fig. 2). 

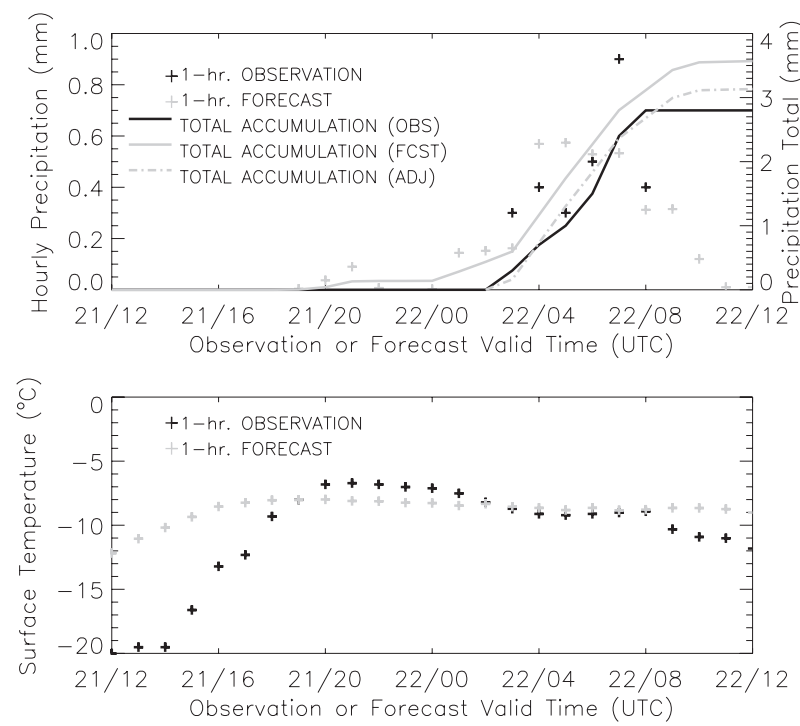

FIG. 2. Comparison of the modeled and observed (top) precipitation rates and (bottom) 2-m air temperature during the 24-h forecast period. Analysis of precipitation rates include a modified accumulation compensating for model timing errors (ADJ) by integrating model accumulated precipitation only beyond 0200 UTC.

Combinations of aircraft data, balloon soundings, and King City radar reflectivity depict the vertical structure of temperature, humidity and precipitation during the event. At 0400 UTC, radar indicated two distinct layers of cloud and precipitation, separated at an altitude of $4 \mathrm{~km}$ (Fig. 3a). Sounding data indicated a layer from the surface to $4 \mathrm{~km}$ that was nearly saturated (supersaturated) with respect to water (ice), a shallow, unsaturated layer at $4 \mathrm{~km}$, and a third layer from 4 to $6 \mathrm{~km}$ where ice supersaturation was on the order of $10 \%$. A third layer of ice supersaturation was located near $7 \mathrm{~km}$, but ice in this layer was not detected by the King City radar. These layers eventually merged, with intermittent, downward streaks of enhanced reflectivity suggesting a period of active seeder-feeder processes (Rutledge and Hobbs 1983) that likely enhanced precipitation development toward 0600 UTC (Fig. 3b).

By 0600 UTC, the entire vertical column was saturated (supersaturated) with respect to water (ice), producing a deep column through which ice crystals could grow by vapor deposition, accretion, or aggregation (Fig. 3b). Observations from CloudSat around 0600 UTC indicated cloud-top altitudes near $7 \mathrm{~km}$, and identified an area of enhanced precipitation near the CARE site and southernmost portion of the orbital segment, inferred through an increase in radar reflectivity (Fig. 4). At 0624 UTC, dual-polarimetric parameters suggested a deep layer of aggregation in the lowest $2 \mathrm{~km}$, marked by an increase in horizontally polarized radar reflectivity (Fig. 5).
Differential reflectivity decreased sharply across the 2-km level as individual, horizontally oriented crystals transitioned to larger aggregates with irregular shapes and no preferred orientation. As the cyclone departed and synoptic-scale forcing waned, cloud depths were reduced to $3 \mathrm{~km}$ or less, and precipitation rates decreased (Fig. 3c).

\section{b. Aircraft vertical profiles}

As part of the 22 January 2007 intensive observing period, the NRC Convair-580 sampled clouds and precipitation in the vicinity of the King City radar, the CloudSat flight track, and CARE site instrumentation (Fig. 1). Previous studies have demonstrated that the parameters of an exponential size distribution evolve from cloud top to cloud base, and are often related to temperature as small crystals collide and aggregate (Houze et al. 1979; Lo and Passarelli 1982; Heymsfield et al. 2002; Field and Heymsfield 2003; Heymsfield et al. 2007). This analysis focuses on two profiles: a descending aircraft spiral obtained in the vicinity of the CARE site, and the ascending departure from the CARE site on an eastsoutheast heading (Fig. 1). Although some previous studies have incorporated Lagrangian spirals (Lo and Passarelli 1982), the spiral described here descended at a rate of 3-5 $\mathrm{m} \mathrm{s}^{-1}$, sampling the broad characteristics of crystal populations over the CARE site instrumentation. Combined, the two profiles include observations between 0600 and 0700 UTC, but are assumed to be broadly representative of precipitation that occurred during the hour, as King City radar observations indicated little change in the coverage or intensity of precipitation during the same time period. Although crystal probe imagery, radar sampling, and the aircraft vertical profiles of temperature and moisture were obtained at slightly different time periods and locations, qualitative comparisons are justified by the steady-state nature of the precipitation shield.

The aircraft was equipped with Particle Measuring Systems (PMS) 2D-C (15 $\mu \mathrm{m}-0.96 \mathrm{~mm})$ and 2D-P (0.2$6.4 \mathrm{~mm}$ ) probes capable of measuring crystal diameters and number concentrations. During the descending aircraft spiral, crystal probe imagery indicated that aggregates were present throughout the bulk of the vertical column, appearing at temperatures as cold as $-27^{\circ} \mathrm{C}$ (Fig. 6). Aircraft spiral data obtained approximately $35 \mathrm{~km}$ northwest of the King City radar indicate a rapid increase in aggregate size near the 3-km level, coincident with a marked increase in horizontally polarized radar reflectivity and transition to lower values of differential reflectivity (Fig. 5). Aircraft probes sampled an environment that was saturated with respect to water and with ambient temperature of approximately $-12^{\circ} \mathrm{C}$, supportive of branched crystal development, growth, and aggregation (Pruppacher and 
(a)

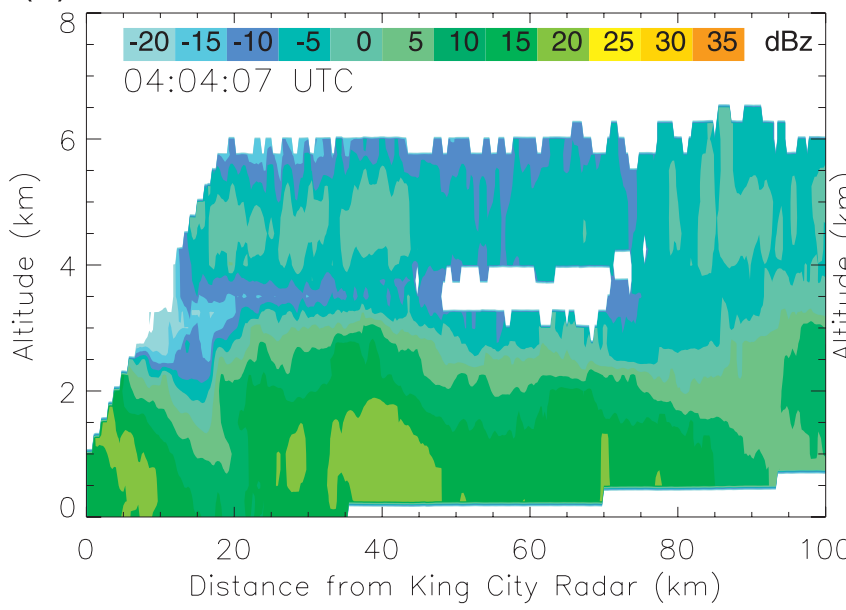

(b)

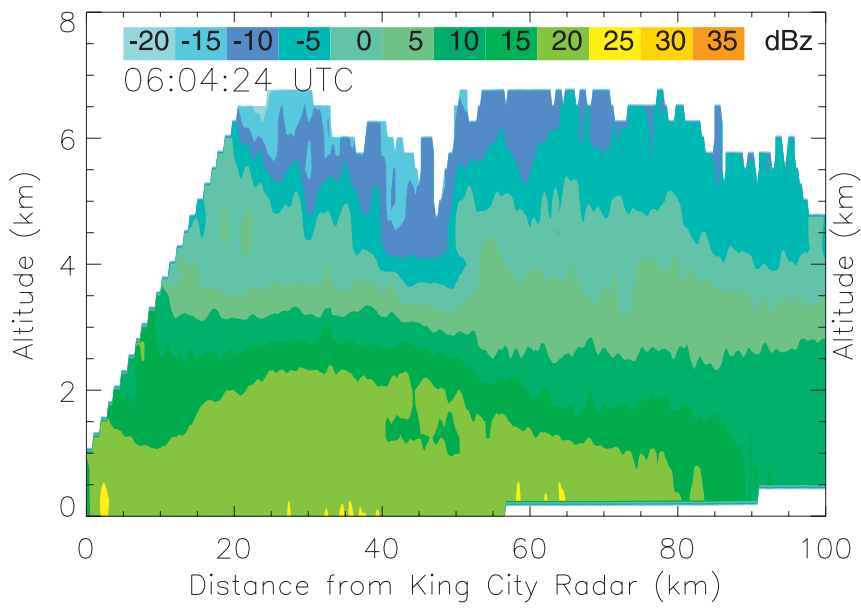

(c)

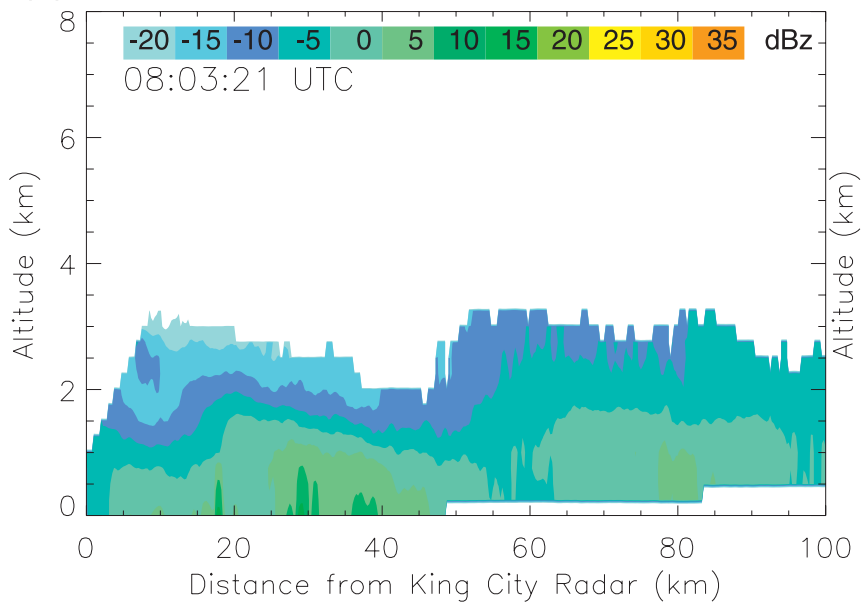

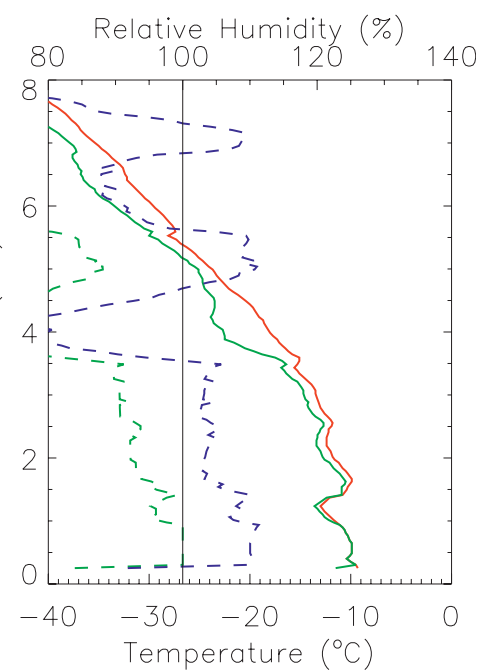
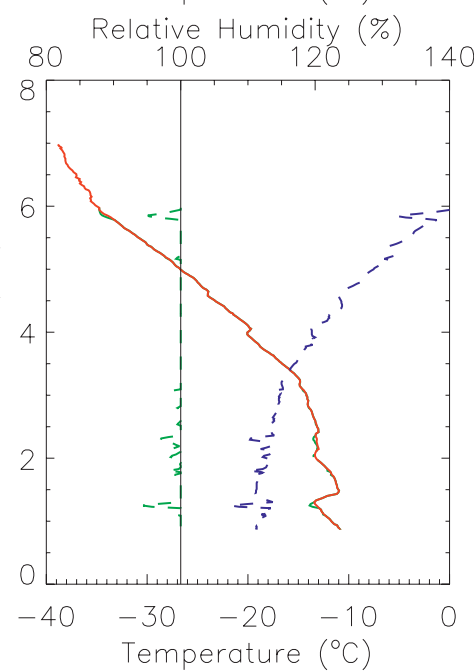

$80 \begin{array}{rrr}\text { Relative Humidity } \\ 100 & 120 & 14 \\ 8 & 100\end{array}$

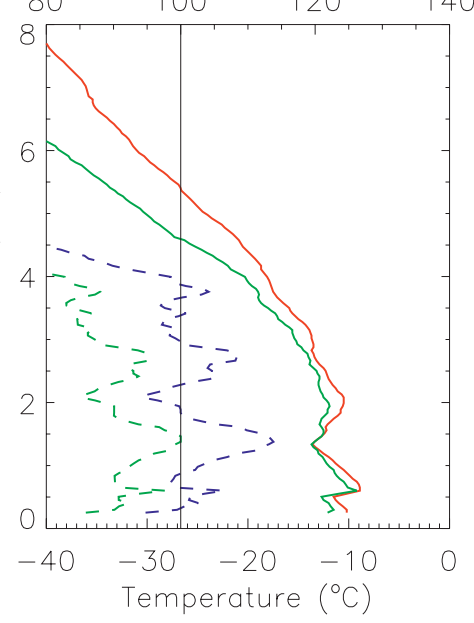

FIG. 3. Radar reflectivity cross sections obtained from the King City radar along the $331^{\circ}$ azimuth, in the direction of the CARE site. (a) Radar reflectivity and CARE site radiosonde profile of temperature (red) and dewpoint (green) valid at 0400 UTC. Dashed lines depict relative humidity with respect to water (green) and ice (blue). (b) As in (a), but valid around 0600 UTC. Temperature and moisture profiles are provided by aircraft spiral data. (c) As in (a), but valid around 0800 UTC. In (a)-(c), the CARE site is located approximately $35 \mathrm{~km}$ northwest of the King City radar location. 

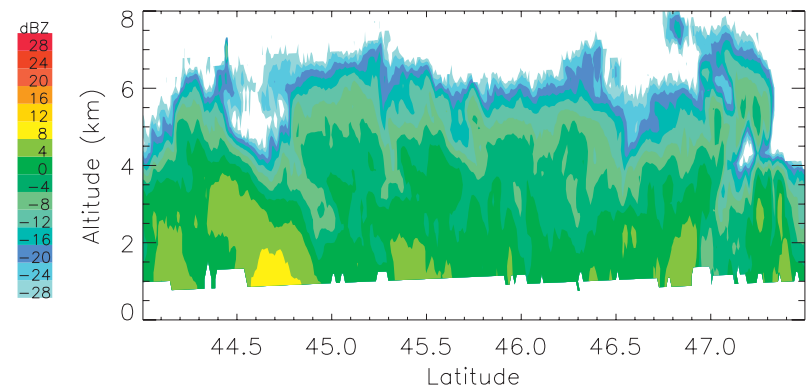

FIG. 4. CloudSat radar reflectivity profiles of snowfall occurring across the C3VP operational domain around 0600 UTC 22 Jan 2007. Observations are taken from the orbital segment in Fig. 1.

Klett 1978). The deep layer of water (ice) saturation (supersaturation) likely encouraged some riming of crystals and enhanced the development of crystal aggregates, but digital photographs of crystals at the surface indicated that any riming that occurred was light, and did not shroud the entire crystalline structure (Petersen et al. 2007).

Imagery from crystal probes were converted to ice crystal size distributions and postprocessed by A. Heymsfield, accommodating the overlap in the size ranges of the $2 \mathrm{D}-\mathrm{C}$ and 2D-P systems and eliminating the effects of shattered crystals, which are detrimental to the calculation of size distribution parameters (Heymsfield et al. 2008). The resulting size distributions were available in 5-s increments of aircraft flight time. The moment fitting method of Heymsfield et al. (2002) was used to estimate the intercept $N_{\text {os }}$ and slope $\lambda_{s}$ of an exponential size distribution, based on calculations of the first and second moments of the observed size distributions. To focus on the highestquality data, moment-fit estimates of $N_{\text {os }}$ and $\lambda_{s}$ were only retained herein if they produced a fitted size distribution that was strongly correlated to observations $\left(R^{2} \geq 0.8\right)$. Although threshold values of $R^{2}$ have varied in other studies from 0.6 (Heymsfield 2003) to 0.8 (Heymsfield et al. 2004), the value of $R^{2} \geq 0.8$ was used here to compare model assumptions against the highest-quality data.

\section{c. Calculation of snow bulk density}

Within the Goddard scheme, the mass-diameter relationship for a population of spherical crystals is described in terms of a fixed, effective bulk density, which defaults to $\rho_{s}=100 \mathrm{~kg} \mathrm{~m}^{-3}$. Heymsfield et al. (2004) described a technique to obtain an effective population bulk density $\left(\rho_{e}\right)$ based upon aircraft measurement of ice water content and the total volume of spheres represented within a given size distribution. The mass-diameter relationship of Heymsfield et al. (2004) was used to calculate the total ice water content from sampled populations of ice crystals, where $a_{m}=0.077 \mathrm{~kg} \mathrm{~m}^{-b_{m}}$ and $b_{m}=2.05$, (a)

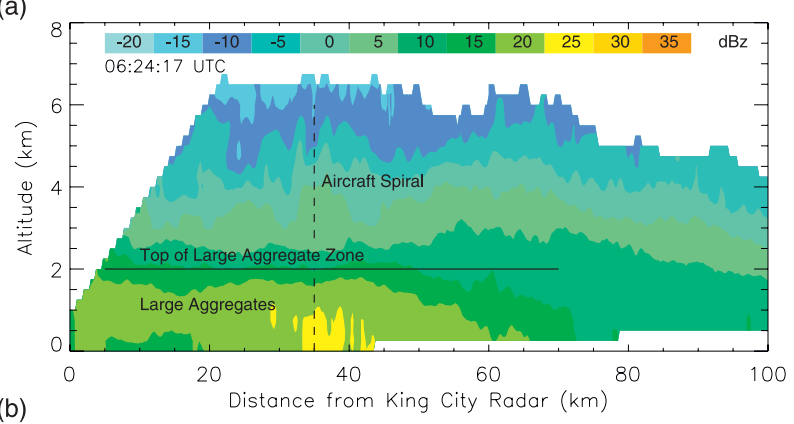

(b)

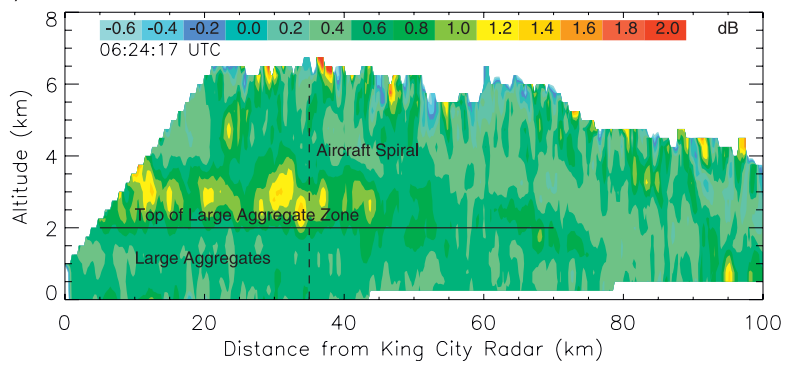

FIG. 5. Cross sections of (a) horizontally polarized radar reflectivity and (b) differential reflectivity, obtained from the King City radar at 0624 UTC along the $331^{\circ}$ azimuth, in the direction of the CARE site. The approximate location of the aircraft spiral is indicated in (a) and (b).

a relationship obtained from a large number of aircraft samplings within convectively driven cirrus and stratiform ice clouds.

Estimates from the Heymsfield et al. (2004) relationship can be checked against observations by examining the ratio of calculated ice water content to counterflow virtual impactor (CVI; Twohy et al. 1997) measurements obtained aboard the NRC Convair-580. Pairs of calculated and measured ice water content indicate that the calculated ice water content (IWC) often exceeds the CVI measurement, with the resulting scatterplot suggesting that the best fit occurs for measured and calculated values between 0.01 and $0.2 \mathrm{~g} \mathrm{~m}^{-3}$ (Fig. 7a). Ratios were binned at intervals of $20 \%$, resulting in a rightskewed distribution with a median of 1.38 and standard deviation of 0.93 (Fig. 7b). The clustering of ice water content ratios between 0.8 and 1.2 is appropriate, given the use of a fixed mass-diameter relationship and CVI errors of $11 \%$ ( $23 \%)$ for condensed total water contents of $0.2 \mathrm{~g} \mathrm{~m}^{-3}\left(0.01 \mathrm{~g} \mathrm{~m}^{-3}\right)$ as reported by Heymsfield et al. (2005). The greatest ice water contents measured by the CVI were obtained in the lowest $1-2 \mathrm{~km}$ of the aircraft profile and from large aggregates, which differ from the smaller particles of cirrus and ice clouds that are best represented by the Heymsfield et al. (2004) relationship. The Heymsfield et al. (2004) relationship is applied to volumes dominated by large diameter 


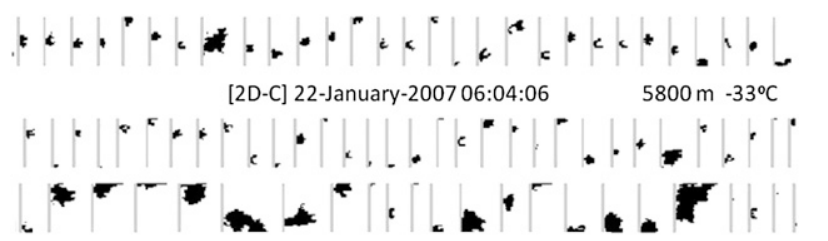

[2D-C] 22-January-2007 06:08:20 $4875 \mathrm{~m}-27^{\circ} \mathrm{C}$
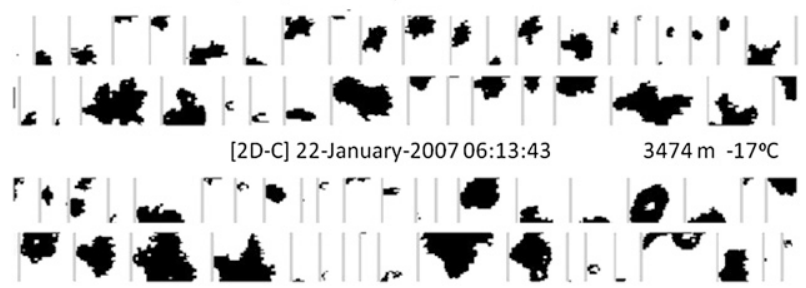

[2D-C] 22-January-2007 06:15:37 2948 m -15² C

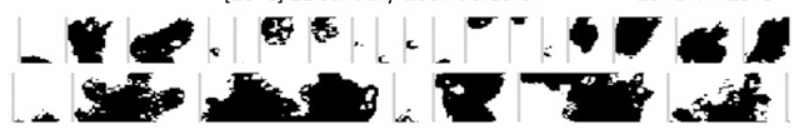

[2D-C] 22-January-2007 06:17:29

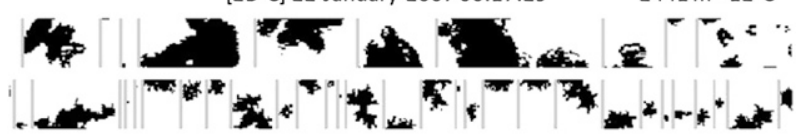

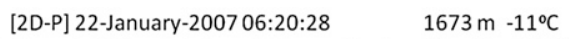

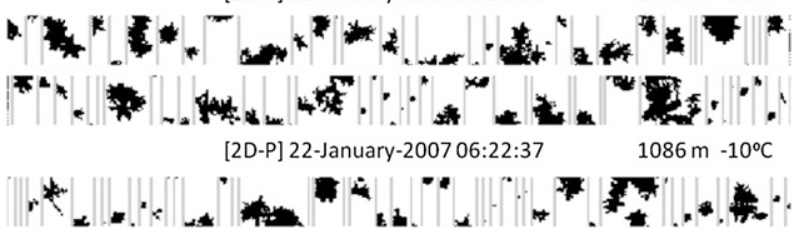

FIG. 6. Images of crystals obtained by aircraft probes during the descending spiral, representative of habits within size distributions at various altitudes. Note that the bottom two cases are from the 2D-P system, which better depicts the structure of the largest aggregates that begin to overwhelm the $2 \mathrm{D}$-C probes at higher altitudes. The altitude and temperature for each crystal set was approximated by matching the published time stamp to aircraft flight data.

aggregates represented by low values of $\lambda_{s}$, since these large aggregates likely include numerous ice-free areas.

Calculations of $\rho_{s}$ presented here utilize the Heymsfield et al. (2004) relationship estimating the total ice water content within each size distribution, divided by the total volume of equivalent diameter spheres, with sizes reported as the center of each size bin. Given the median ratio of estimated and measured ice water content is 1.38 , it is expected that values will present a slight, high bias in estimates of $\rho_{s}$ but will demonstrate vertical variability within observations for comparison against a fixed value approach used within the Goddard microphysics scheme.

\section{Simulation of the 22 January 2007 snowfall event}

Previously, Shi et al. (2010) used the Advanced Research Weather Research and Forecasting model (ARW-WRF), the Goddard scheme, and other parameterizations to create a triply-nested, high-resolution simulation of the 20-23 January 2007 period, which encompassed both the synoptic-scale event and a precursor, lake-effect snowfall case. Simulations by Shi et al. (2010) were capable of depicting the evolution of both mesoscale, lake-effect precipitation bands on 20-21 January 2007 and the broader, synoptic-scale event of 22 January 2007 that followed, including detailed cloud structures within the highest-resolution $(1 \mathrm{~km})$ domain. The Shi et al. (2010) selection of domains and use of the Goddard microphysics scheme is repeated here, but with a reduced number of vertical levels and with remaining parameterizations selected to parallel experimental, real-time forecasts produced by the National Severe Storms Laboratory as part of the 2009 NOAA Hazardous Weather Testbed Spring Experiment (J. Kain 2009, personal communication). Forecast model parameterizations are provided in Table 1 with nested grid coverage shown in Fig. 8. Simulations were initialized at 1200 UTC 21 January 2007 and continued for $24 \mathrm{~h}$, with initial and boundary conditions supplied by 6-hourly analyses from the NCEP Global Forecast System at $1^{\circ}$ spatial resolution. Minor differences in precipitation intensity and extent were observed among the nested grids, and only the results of the $1-\mathrm{km}$ domain will be discussed here.

An evaluation of model performance requires a simulation of the event that reasonably depicts the conditions sampled by C3VP instrumentation. To demonstrate that the model forecast produced a reasonable depiction of the observed distribution and timing of precipitation, simulated hourly precipitation rates are compared against instantaneous rates estimated from King City radar reflectivity at the $0.8^{\circ}$ elevation angle, using a relationship specifically tuned for the event by Huang et al. (2010) (Fig. 9). The heaviest precipitation occurred due north of the radar at 0600 UTC, then extended through the northeastern quadrant. Coverage of radar estimated precipitation rates are reduced with range as the radar beam altitude increases with range and samples above the zone of large aggregates and greatest reflectivity. An examination of surface data indicates that the model had difficulty representing the diurnal cycle of temperature and overestimated the duration of precipitation at the surface (Fig. 2), with precipitation beginning at 2000 UTC 21 January 2007 and continuing through 1000 UTC 22 January 2007. Although the model forecast suffered from errors in timing, the spatial extent was appropriate, and the prediction of hourly precipitation rates followed the trend of observations at hours when precipitation was actually observed (Fig. 2b).

In general, both the model and observations produce a similar distribution of light to moderate precipitation rates within $50 \mathrm{~km}$ of the King City radar, and WRF 

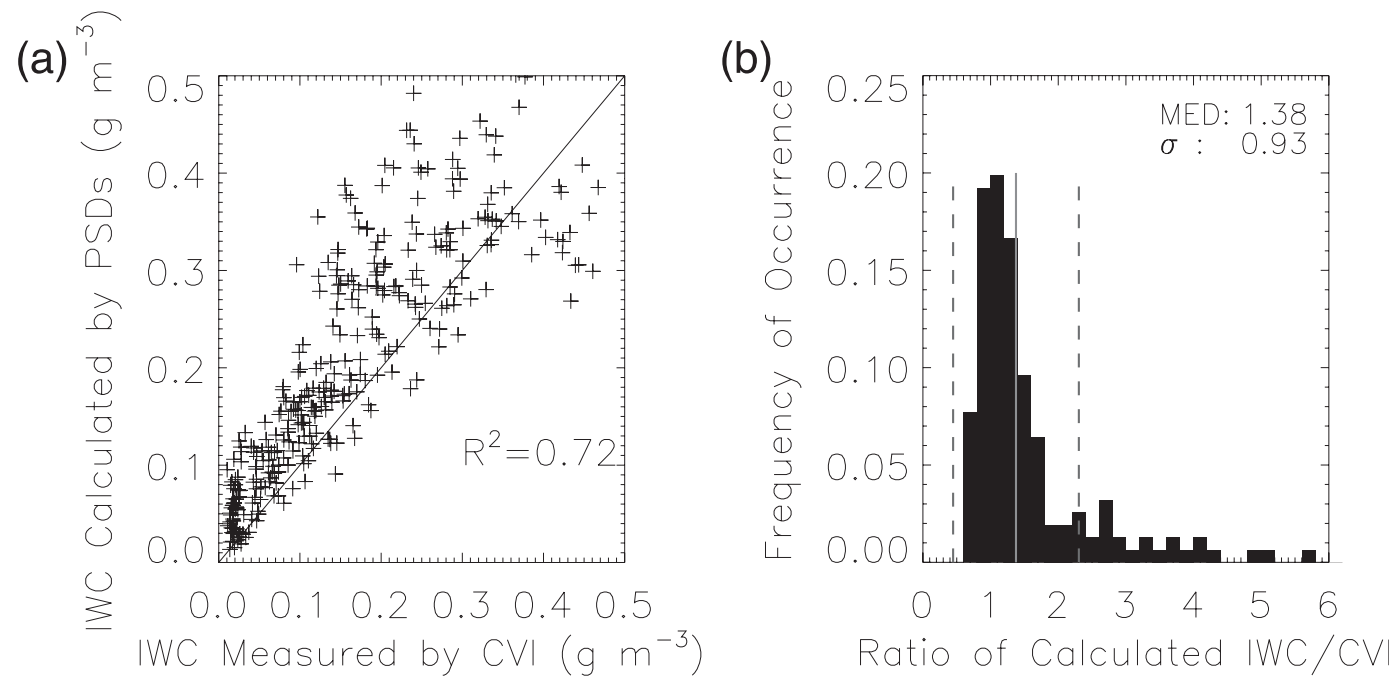

FIG. 7. Comparisons of the ice water content measured by the aircraft counterflow virtual impactor probe vs calculation from particle size distributions and the mass-diameter relationship of Heymsfield et al. (2004), combining the profiles obtained during the descending spiral and departure ascent. (a) Scatterplot of calculated and measured total ice water contents. (b) Histogram of the ratio of calculated and measured total ice water content.

model profiles were extracted within a 50-km radius of the King City radar to provide comparisons to aircraft data. This selection of model profiles encompasses the descending spiral and bulk of the departure ascent, the instrumentation at the CARE site, and provides a large sample representing the properties of snowfall within the forecast domain. Output from the model valid time of 0600 UTC 22 January 2007 is used because it provides the best temporal fit to the aircraft profiles and the CloudSat overpass. Spatial patterns of simulated and observed precipitation varied little through 0700 UTC.

\section{a. Comparisons of model and aircraft vertical profiles}

Conditional mean profiles of hydrometeor content are used in comparisons, including only the grid points and vertical levels with nonzero values. The aircraft CVI and calculated estimates of ice water content indicate discrete layers of enhanced ice water content approximately $0.25 \mathrm{~km}$ thick at altitudes of 1 and $2 \mathrm{~km}$, but these features were not represented in the forecast mean vertical profile (Fig. 10a). Radar observations indicated a higher altitude, distinct cloud layer from 4 to $6 \mathrm{~km}$ at 0400 UTC (Fig. 3a), which could have seeded the layer below and locally enhanced the ice water content as these populations continued to fall. The aircraft temperature profile suggests that these layers were within regions of conditional instability with embedded convection, but no cellular or banded structures were apparent in King City radar imagery, and measurements of vertical velocity were not available. Layers of increased IWC present in observations but not within the model mean profile may be the result of seeder-feeder processes that were not predicted by the model forecast, occurred on vertical scales that the combined model dynamics, vertical grid spacing, and spatial averaging were incapable of representing, or

TABLE 1. Configuration of the Advanced Research WRF model, version 2.2, for simulation of the 22 Jan 2007 snowfall event.

\begin{tabular}{lll}
\hline \multicolumn{1}{c}{ Physical process } & Parameterization scheme & \multicolumn{1}{c}{ References } \\
\hline Boundary layer & Mellor-Yamada-Janjić & Janjić (1990, 1996, 2001) \\
Longwave radiation & Rapid radiative transfer & Mlawer et al. (1997) \\
Shortwave radiation & Dudhia scheme & Dudhia (1989) \\
Land surface processes & Noah land surface model & Ek et al. (2003) \\
Cloud microphysics & Goddard scheme & W.-K. Tao et al. (2008, \\
& & personal communication) \\
9-km cumulus parameterization & Grell-Devenyi scheme & Grell and Devenyi (2002) \\
Saturation adjustment & Goddard scheme & Tao et al. (2003) \\
Horizontal grid spacing & $9-3-1 \mathrm{~km}$ & Shi et al. (2010) \\
Time step & $30-10-3 \mathrm{~s}$ & Shi et al. (2010) \\
Vertical levels & 34 & Shi et al. (2010) \\
\hline
\end{tabular}




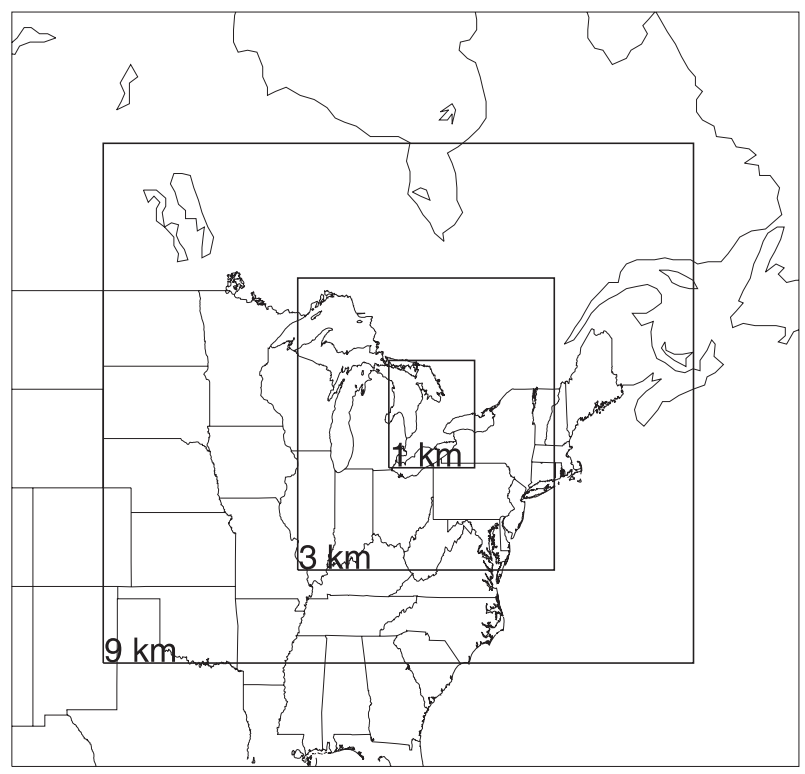

FIG. 8. Graphical depiction of the triply nested grids and varying resolutions used by Shi et al. (2010), and replicated for use in simulations of the 22 Jan 2007 snowfall event.

represent a mismatch between the evolution of the simulated storm and processes sampled by the aircraft. Graupel was not predicted in the vicinity of the CARE site, in agreement with aircraft observations (Fig. 6), digital photographs of precipitating crystals (Petersen et al. 2007), and the results of Shi et al. (2010).

Profiles of temperature and relative humidity with respect to water or ice were obtained on the WRF model vertical levels without further interpolation. Large discrepancies occur between the model and aircraft profiles between 3 and $4 \mathrm{~km}$ (Fig. 10b). These differences resulted from the use of the Tao et al. (2003) saturation adjustment scheme and temperature threshold in this particular forecast. By applying the threshold at $-15^{\circ} \mathrm{C}$, supersaturation with respect to ice was converted to cloud ice mass, while the sampled environment remained saturated (supersaturated) with respect to water (ice). Similarly, any supersaturation with respect to water leads to additional mass in the cloud water category. Since the saturation adjustment occurs as a final step within the microphysics subroutine, this stages the next model time step with cloud ice and cloud water for advection or additional microphysical processes. In this event, no cloud liquid water was reliably detected by the Rosemount Ice Detector (RICE) probe.

Although a direct comparison of the forecast cloud liquid water content to observations would suggest a forecast error, this error could be alleviated by incorporating the saturation adjustment elsewhere within the flow of the microphysics subroutine. A similar argument can be made for the production of cloud ice, but the resulting ice water content is comparable to observations, whereas liquid water was not detected. An examination of the model mean temperature profile reveals a persistent warm bias throughout the vertical column (Fig. 10c), and a component of the bias may be the result of excessive deposition during the saturation adjustment process. The warm bias in temperature may also result from the initial and boundary conditions, or other simulated physical processes.
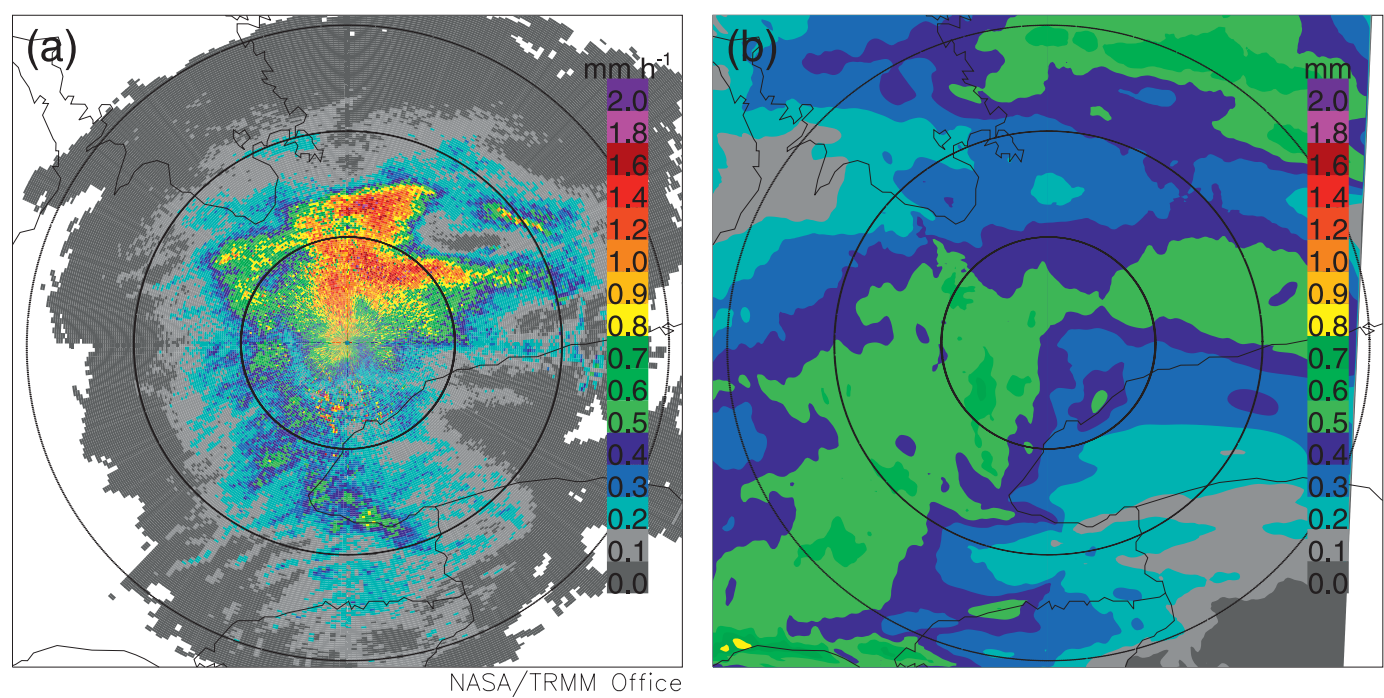

FIG. 9. (a) Instantaneous, liquid equivalent precipitation rate estimated from the King City radar at 0600 UTC, based upon the relationship proposed by Huang et al. (2010) for the event and radar reflectivity at $0.8^{\circ}$ elevation angle. (b) Liquid equivalent, 1-h accumulated precipitation within the model domain, ending at 0600 UTC 22 Jan 2007. Both (a) and (b) are centered on the location of the King City radar with range rings provided at 50-km intervals. 

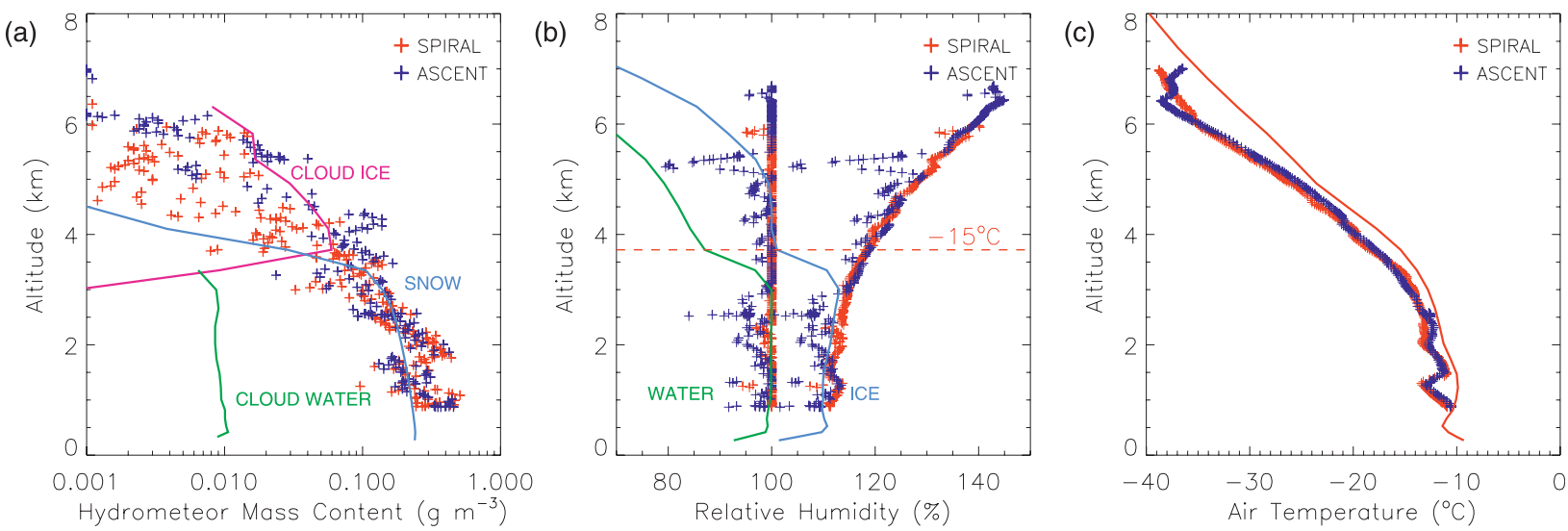

FIG. 10. Comparisons of model vertical profiles and available aircraft data, based upon grid points within $50 \mathrm{~km}$ of the King City radar. (a) Conditional mean profiles of hydrometeor mass content, compared with aircraft profile estimates of ice and liquid water content. (b) Model vertical profiles of saturation with respect to water (green line) and ice (blue line) compared to aircraft spiral data shown with symbols. (c) Profiles of air temperature. Colored symbols refer to the descending aircraft spiral and departure ascent shown in Fig. 1.

\section{b. Size distribution parameters and snow bulk density}

Mean profiles of the size distribution slope parameter were calculated based on (3), the fixed values of the distribution intercept, and fixed value of effective bulk density. Each distribution parameter can be compared against observations from aircraft profiles to determine if the Goddard scheme assumptions accurately represent their magnitudes and vertical variability. The use of a fixed distribution intercept $\left(N_{\mathrm{os}}=1.6 \times 10^{4} \mathrm{~mm}^{-1} \mathrm{~m}^{-3}\right)$ does not represent the general increase in $N_{\text {os }}$ with height (Fig. 11a). Aircraft-measured values span two orders of magnitude, while the constant value of $N_{\text {os }}$ represents conditions only near the $3-\mathrm{km}$ level. Profiles obtained during the C3VP campaign are comparable to previous field campaigns sampling ice crystals. Houze et al. (1979) and Heymsfield et al. (2002) have demonstrated variability in $N_{\text {os }}$ with temperature or altitude, although functional relationships vary among events. Except near the cloud top, estimates of $\rho_{s}$ suggest that the default value of $100 \mathrm{~kg} \mathrm{~m}^{-3}$ in the Goddard scheme was rarely observed. Instead, density decreased toward the cloud base in a manner similar to the slope parameter (Fig. 11b), as suggested by Heymsfield et al. (2004).

Below $3 \mathrm{~km}$, the mean profile of simulated $\lambda_{s}$ overestimates values observed from either aircraft profile, implying that the model produced a size distribution with mean crystal size $\left(\bar{D}=\lambda_{s}^{-1}\right)$ smaller than observed (Fig. 11c). The ascending aircraft profile indicates a smooth increase in $\lambda_{s}$ with height and is presumed to be representative of the broader precipitation shield, with (a)

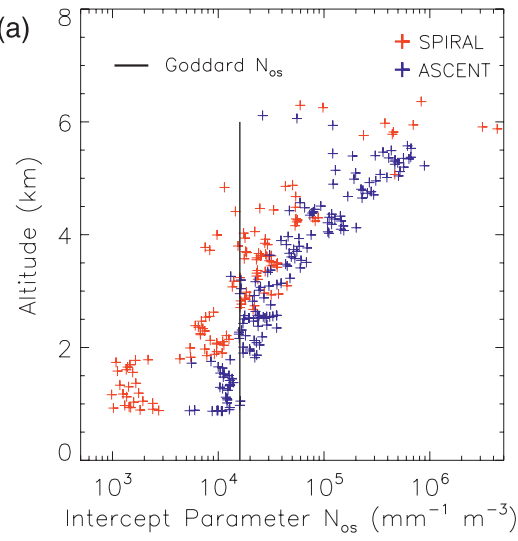

(b)

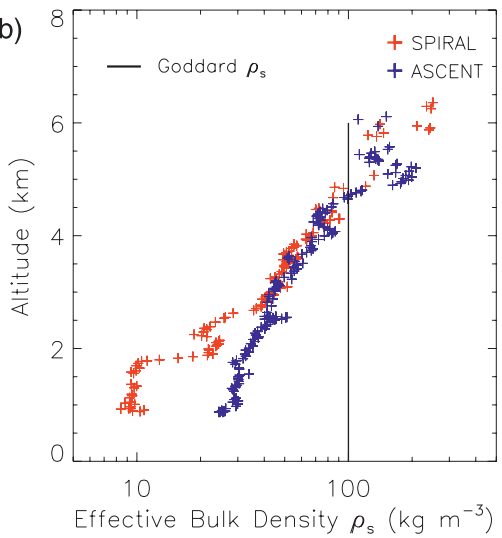

(c)

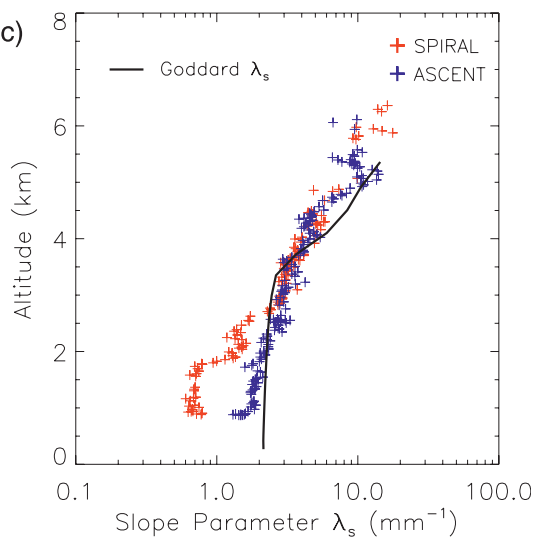

FIG. 11. (a) Aircraft observations of the snow crystal size distribution intercept $N_{\mathrm{os}}$ vs the fixed value (line) within the Goddard microphysics scheme. (b) Aircraft estimates of effective bulk density $\rho_{s}$ based upon measured particle size distributions and the massdiameter relationship of Heymsfield et al. (2004) vs the fixed value (line) within the Goddard scheme. (c) Profiles of $\lambda_{s}$ based upon the mean profile of simulated snow content, constant $N_{\mathrm{os}}$ and $\rho_{s}$, compared with aircraft estimates from observed particle size distributions. Crosshairs $(+)$ indicate data from the descending aircraft spiral (departure ascent) shown in Fig. 1. 
$\lambda_{s}$ approaching $1 \mathrm{~mm}^{-1}$ near the cloud base. The value of $1 \mathrm{~mm}^{-1}$ is comparable to previous observations by Houze et al. (1979) or Lo and Passarelli (1982), and the minimum value provided in a summary parameterization of $\lambda(T)$ by Ryan (2000). The Goddard scheme produced a steady value near $2.1 \mathrm{~mm}^{-1}$, continued through a depth of $3 \mathrm{~km}$, suggesting that the arithmetic mean size of simulated crystals was nearly invariant and smaller than suggested by observations.

When a constant density and intercept are applied within the single-moment framework, it implies that the slope parameter in (3) will vary only as an inverse function of the snow mass content. In the altitude range of 3-4 km, cloud ice accumulated within the Goddard scheme contributes to snow through autoconversion and accretion, implying that small ice crystals are aggregating into largersized particles while consuming smaller droplets or other crystals. This causes a sharp increase in the snow content from 3 to $5 \mathrm{~km}$. At altitudes below $3 \mathrm{~km}$, the simulated profile of snow content generates a profile of $\lambda_{s}$ with minimal variability. Stagnant $\lambda_{s}$ values in the lowest $3 \mathrm{~km}$ are contrary to aircraft observations indicating that $\lambda_{s}$ continued to decrease steadily toward the cloud base. In terms of mean crystal size, the microphysics scheme produced a profile with little variability below $2 \mathrm{~km}$, while the mean size from observed distributions continued to grow. Naturally occurring crystals continued to aggregate, as observed in the reduced number concentrations of small particles $\left(N_{\mathrm{os}}\right)$, an increase in their mean size, inferences from dual-polarimetric radar parameters (Fig. 5), and crystal probe imagery (Fig. 6). The effects of aggregation on size distribution parameters are not well represented by an approach utilizing a fixed intercept and density, where variability in $N_{\mathrm{os}}$ and $\lambda_{s}$ are reduced.

Above the $3-\mathrm{km}$ level, comparisons between the Goddard scheme assumptions and aircraft data are complicated by the separation of cloud ice and snow categories within the model simulation. This division implies that the model expects a rapid transition from lower-density aggregates to monodisperse $(20 \mu \mathrm{m})$, pure ice spheres composing the cloud ice category. Particles as large as $1 \mathrm{~mm}$ were observed at altitudes of 5-6 km (not shown), but the Goddard scheme predicted that cloud ice crystals would dominate. Reliable fits to exponential size distributions were frequently obtained in the same altitude range, indicating that crystal populations could be represented by a complete size distribution rather than a monodisperse assumption (Fig. 11). Combined with observed bulk densities less than pure ice, the cloud ice particles simulated at the cloud top do not accurately represent the size distribution or density characteristics of the observed crystal populations. The Goddard scheme could be improved upon by prescribing a size distribution and density to the cloud ice category that blends with the properties of simulated aggregates. By incorporating a size distribution for these particles, their size distribution and fall speeds could be blended within the deeper layer of snow below, reducing the sharp transition present near $4 \mathrm{~km}$.

\section{c. Evaluation of the snow terminal velocity- diameter relationship}

Given a size distribution and mass-diameter relationship, the resulting precipitation rate depends upon the fall speeds of individual crystals. Locatelli and Hobbs (1974) proposed a power-law fit between the diameter of a crystal or aggregate and its terminal velocity, and a comparable relationship can be determined for the 22 January 2007 event, using data from the Hydrometeor Velocity and Shape Detector (HVSD; Barthazy et al. 2004). The HVSD is a ground-based instrument that images crystals as they pass between a series of detectors, and repeated snapshots of individual crystals are used to estimate their fall speeds. During this event, the HVSD was deployed at the CARE site and output data were examined by Gyuwon Lee (McGill University 2009, personal communication) to ensure that the crystal fall speeds were not biased by winds during the event. It is assumed here that the reported velocity is the terminal velocity for each crystal.

Observations of crystal sizes and fall speeds were assembled into a joint histogram, using the observed bin sizes for diameter and velocities of $5 \mathrm{~cm} \mathrm{~s}^{-1}$, respectively. Size and velocity was determined for over 11000 individual flakes observed between 0200 and 0800 UTC (Fig. 12). Paired observations of size and velocity were fit to a power law of the form $V(D)=a_{v} D^{b_{v}}$ through least squares minimization, following Locatelli and Hobbs (1974), but restricted to size bins larger than $1 \mathrm{~mm}$ with at least 50 observations. These restrictions were applied because the HVSD has difficulty detecting particles smaller than $1 \mathrm{~mm}$, and the fit should not be biased by small number concentrations of the largest crystals.

The crystals retained for calculation of the power-law fit produced a terminal velocity-diameter relationship similar to the Locatelli and Hobbs (1974) category of "unrimed radiating assemblages of dendrites," as both the coefficient $a_{v}=2.146 \mathrm{~m}^{1-b} \mathrm{~s}^{-1}$ and exponent $b_{v}=0.145$ were similar to their reported values of $a_{v}=1.671 \mathrm{~m}^{1-b} \mathrm{~s}^{-1}$ and $b_{v}=0.16$ (Fig. 12). The resemblance between the Locatelli and Hobbs (1974) fit for aggregates and the relationship derived from HVSD data is supported by the appearance of aggregates throughout the spiral descent profile sampled by the aircraft probes (Fig. 6), inference from dual-polarimetric radar parameters (Fig. 5), and photographs acquired at the surface (Petersen et al. 2007). Differences in measurement style also contribute, as 


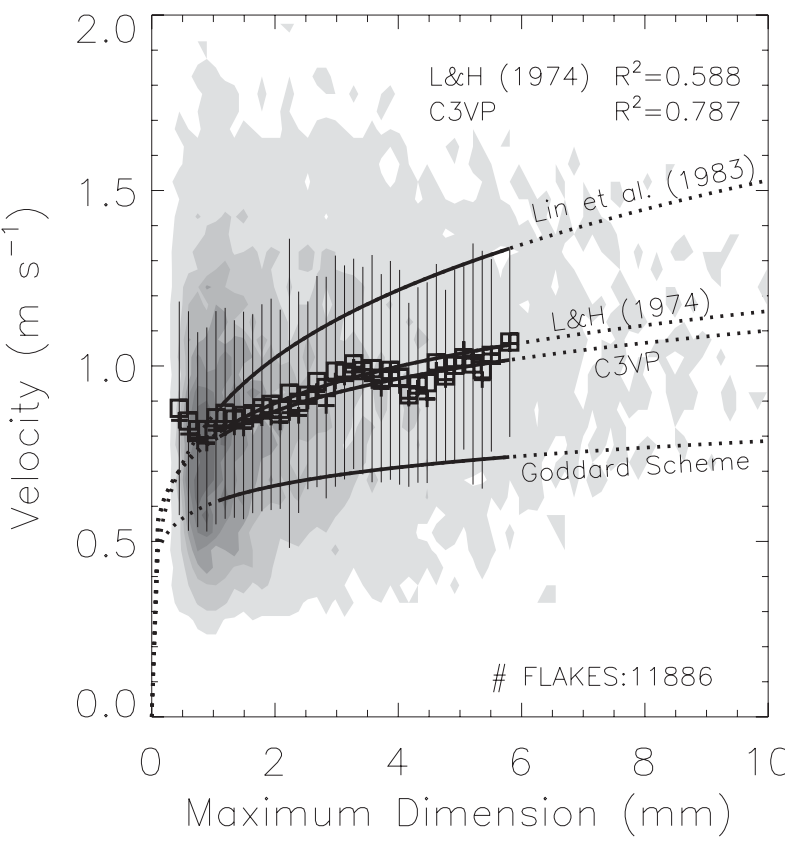

FIG. 12. Joint histogram of crystal maximum dimension and HVSD estimate of terminal fall speed along with proposed fits by Locatelli and Hobbs (1974), Lin et al. (1983), and W.-K. Tao et al. (2008, personal communication). Mean (crosshair), median (open square) and standard deviation of terminal velocities are plotted for each size bin where data were sufficient $(N \geq 50)$ for providing a best-fit estimate. Relationships are extrapolated for sizes smaller than $1 \mathrm{~mm}$ and less than 50 occurrences (dashed). Histogram shading is performed at $1 \%, 10 \%$, and every $10 \%$ thereafter.

the HVSD data reported the maximum crystal dimension and Locatelli and Hobbs (1974) used an equivalent diameter circle. The strong correlation $\left(R^{2}=\right.$ 0.787 ) for the power-law relationship derived from the HVSD suggests a reliable representation, although the histogram exhibits a large amount of scatter in fall speeds for all crystal sizes generally, and especially those smaller than $2 \mathrm{~mm}$ in diameter. The resulting best fit from HVSD data implies a greater fall speed at all crystal sizes than currently assumed within the Goddard scheme, but less than those in the Lin et al. (1983) formulation.

Although the model forecast provided a reasonable prediction of the liquid equivalent precipitation rate, the result was obtained despite a poor representation of the velocity-diameter relationship for crystals observed at the surface. By representing snow crystals as spheres of a constant density, the amount of mass within a simulated particle of a given diameter may exceed the natural particle of equivalent size. The constant value of $\rho_{s}$ exceeds observations, and a sphere $\left(b_{m}=3\right)$ exceeds observed values of $b_{m}$ from 1.8 to 2.2 (Locatelli and Hobbs 1974; Heymsfield et al. 2004). Although a simulated particle of a given diameter may have a terminal velocity less than observations, an expected reduction in mass flux or precipitation rate may be offset by an overestimate of the mass assigned to each particle. Errors in the size distribution compensate by reducing the arithmetic mean size $\left(\lambda_{s}^{-1}\right)$, and combine with the mass-diameter and diameter-fall speed relationships to produce a reasonable surface accumulation rate. Attempts to validate and improve upon quantitative precipitation forecasts must be comprehensive and address all characteristics of the particle size distribution, mass-diameter, and diameter-fall speed relationships in order to properly account for accretion terms, other interactions among precipitating cloud species, and their resulting precipitation rates.

\section{Summary and conclusions}

The snowfall event of 22 January 2007 occurred within the operational domain of the C3VP campaign and was observed by radar, aircraft, and surface instrumentation. The WRF model, in conjunction with the Goddard sixclass, single-moment microphysics scheme and other physical parameterizations, was capable of simulating the overall structure and evolution of the precipitation. Validation efforts using temperature and liquid equivalent precipitation rate demonstrated that a high-resolution forecast model can recreate the sensible weather of the event, but comparisons to aircraft data demonstrate several opportunities to improve upon ice crystal representation in support of satellite retrieval development.

The use of a fixed distribution intercept and snow density lack the diversity present in aircraft measurements. In aircraft profiles, the distribution intercept and density decreased toward the cloud base as snow crystal distributions transitioned to larger sizes of low density aggregates. The assumed density of $\rho_{s}=100 \mathrm{~kg} \mathrm{~m}^{-3}$ exceeded aircraft-estimated values throughout the bulk of the aircraft ascending profile, and when combined with the fixed distribution intercept, limited the range in model-simulated values of $\lambda_{s}$ to portions of the profile where snow content varied. The resulting size distributions generally produced crystal populations with a smaller mean size (larger $\lambda_{s}$ ) than suggested by aircraft data, particularly in the lowest $2 \mathrm{~km}$ where crystal probe imagery and dual-polarimetric radar indicated significant aggregation. Within the 3-6-km layer, the Goddard scheme predicts a separation of ice water into monodisperse cloud ice and size distributed aggregate categories, resulting in a sharp contrast in ice crystal characteristics, contrary to aircraft observations. This implies that the model separation of cloud ice and snow is less applicable in this case of deep, snowing profiles. Instead, the scheme may benefit from a comparable size distribution for the cloud ice category that allows for particle densities less than pure ice. 
In this specific case, the Tao et al. (2003) saturation adjustment scheme contributed to errors in the vertical profile of water vapor. Although aircraft observations indicated that the vertical column was saturated with respect to water and supersaturated with respect to ice, the saturation adjustment step eliminated all supersaturation with respect to ice at temperatures colder than $-15^{\circ} \mathrm{C}$. Other microphysical processes eliminate supersaturation with respect to ice (e.g., vapor deposition to snow), but the saturation adjustment scheme is arbitrary in its application of a temperature threshold. Saturation adjustment steps could be modified to avoid dependence on a single temperature threshold. Korolev and Isaac (2006) reported a temperature dependence for relative humidity within mixed-phase and ice clouds, which may improve upon simulations of the water vapor profile.

Although the model reproduced the liquid equivalent precipitation rate at the surface, the terminal velocitydiameter relationship used within the Goddard scheme underestimated fall speeds across the full range of diameters observed by the HVSD. Increasing the terminal velocities across the full range of aggregate diameters will increase the precipitation rate and may degrade the forecast simulation described here, but should be considered as a means of improving the physical representation of the snow category. Expected increases in precipitation rate from the increase in terminal velocity may be offset by incorporating a nonspherical mass-diameter relationship and by improving the representation of particle size distributions.

In the single-moment framework, the effects of aggregation on the size distribution must be handled through flexibility in the slope parameter and bulk density, since aggregation is neither a source nor a sink for ice mass. The summary findings of Ryan (2000) claimed that functions of $\lambda_{s}(T)$ are more reliable than $N_{\text {os }}(T)$, providing greater flexibility in size distribution parameters over the current use of a constant intercept. To permit flexibility in the effective bulk density of snow, Heymsfield et al. (2004) suggested that $\rho_{s}$ could be represented as a function of $\lambda_{s}$. Alternatively, Field et al. (2005) used a series of temperature-dependent relationships to incorporate the moments of observed particle size distributions within the microphysical processes of the Thompson et al. (2008) scheme. As an alternative, a double-moment representation within the Goddard scheme would allow for a prediction of the mass content and the total number concentration, allowing for a decrease (increase) in number concentration (size) as crystals approach the cloud base with less reliance on the model temperature profile (Milbrandt and Yau 2005; Morrison et al. 2009). Improvements to the representation of snow crystals, combined with accurate profiles of ice and liquid water content, should contribute to greater forecast accuracy and support the development of retrievals applicable to future satellite campaigns.

Acknowledgments. The authors thank Wei-Kuo Tao and Roger Shi of NASA Goddard Space Flight Center for assistance with the Goddard microphysics scheme in the WRF modeling framework, and three anonymous reviewers for helping to improve the clarity of figures and analysis. Model simulations were performed on the NASA Discover Cluster. Data from the HVSD instrument were provided by GyuWon Lee of McGill University. Petersen acknowledges support from the NASA Precipitation Measurement Mission (via Dr. R. Kakar) and the Global Precipitation Measurement project (via Dr. M. Schwaller). Nesbitt acknowledges support from the Global Precipitation Measurement Project (via Dr. M. Schwaller). Prime funding for aircraft studies during the Canadian CloudSat/CALIPSO Validation Project was provided by the Canadian Space Agency. The lead author was supported in part by the Cooperative Education Program at NASA Marshall Space Flight Center.

\section{REFERENCES}

Barthazy, E., S. Goke, R. Schefold, and D. Hogl, 2004: An optical array instrument for shape and fall velocity measurements of hydrometeors. J. Atmos. Oceanic Technol., 21, 1400-1416.

Bernardet, L., and Coauthors, 2008: The Developmental Testbed Center and its winter forecasting experiment. Bull. Amer. Meteor. Soc., 89, 611-627.

Dudhia, J., 1989: Numerical study of convection observed during the winter monsoon experiment using a mesoscale two-dimensional model. J. Atmos. Sci., 46, 3077-3107.

Ek, M., M. E. Mitchell, Y. Lin, E. Rogers, P. Grunmann, V. Koren, G. Gayno, and J. D. Tarpley, 2003: Implementation of Noah land surface model advances in the National Centers for Environmental Prediction operational mesoscale Eta model. J. Geophys. Res., 108, 8851, doi:10.1029/2002JD003296.

Field, P. R., and A. J. Heymsfield, 2003: Aggregation and scaling of ice crystal size distributions. J. Atmos. Sci., 60, 544-560.

—, R. J. Hogan, P. R. A. Brown, A. J. Illingworth, T. W. Choularton, and R. J. Cotton, 2005: Parameterization of ice-particle size distributions for mid-latitude stratiform cloud. Quart. J. Roy. Meteor. Soc., 131, 1997-2017.

Grell, G. A., and D. Devenyi, 2002: A generalized approach to parameterizing convection combining ensemble and data assimilation techniques. Geophys. Res. Lett., 29, D00A09, doi:10.1029/2007JD009766.

Heymsfield, A. J., 1973: Laboratory and field observations of the growth of columnar and plate crystals and frozen droplets. J. Atmos. Sci., 30, 1650-1656.

_ 2003: Properties of tropical and midlatitude ice cloud particle ensembles. Part I: Median mass diameters and terminal velocities. J. Atmos. Sci., 60, 2573-2591.

_ A. Bansemer, P. Field, S. Durden, J. Stith, J. Dye, W. Hall, and T. Grainger, 2002: Observations and parameterizations of particle size distributions in deep tropical cirrus and stratiform 
precipitating clouds: Results from in situ observations in TRMM field campaigns. J. Atmos. Sci., 59, 3457-3491. , C. Schmitt, C. Twohy, and M. Poellot, 2004: Effective ice particle densities derived from aircraft data. J. Atmos. Sci., 61, 982-1003.

_ - Z. Wang, and S. Matrosov, 2005: Improved radar ice water content retrieval algorithms using coincident microphysical and radar measurements. J. Appl. Meteor., 44, 1391-1412.

_ - A. Bansemer, and C. H. Twohy, 2007: Refinements to ice particle mass dimensional and terminal velocity relationships for ice clouds. Part I: Temperature dependence. J. Atmos. Sci. 64, 1047-1067.

_ P. Field, and A. Bansemer, 2008: Exponential size distributions for snow. J. Atmos. Sci., 65, 4017-4031.

Hong, S.-Y., J. Dudhia, and S.-H. Chen, 2004: A revised approach to ice microphysical processes for the bulk parameterization of clouds and precipitation. Mon. Wea. Rev., 132, 103-120.

Houze, R. A. J., P. V. Hobbs, P. H. Herzegh, and D. B. Parsons, 1979: Size distributions of precipitation particles in frontal clouds. J. Atmos. Sci., 36, 156-162.

Huang, G.-J., V. N. Bringi, R. Cifelli, D. Hudak, and W. A. Petersen, 2010: A methodology to derive radar reflectivity-liquid equivalent snow rate relations using C-band radar and a $2 \mathrm{D}$ video disdrometer. J. Atmos. Oceanic Technol., 27, 637-651.

Hudak, D., H. Barker, P. Rodriguez, and D. Donovan, 2006: Winter precipitation studies with a dual polarized C-band radar. Preprints, European Conf. on Radar in Meteorology and Hydrology, Barcelona, Spain, 1-6.

— , P. Rodriguez, and N. Donaldson, 2008: Validation of the CloudSat precipitation occurrence algorithm using the Canadian C-band radar network. J. Geophys. Res., 113, D00A07, doi:10.1029/2008JD009992.

Janjić, Z. I., 1990: The step-mountain coordinate: Physical package. Mon. Wea. Rev., 118, 1429-1443.

_ 1996: The surface layer in the NCEP Eta model. Preprints, 11th Conf. on Numerical Weather Prediction, Norfolk, VA, Amer. Meteor. Soc., 354-355.

_ 2001: Nonsingular implementation of the Mellor-Yamada level 2.5 Scheme in the NCEP Meso model. NCEP Office Note 437, National Centers for Environmental Prediction, 61 pp.

_ 2003: A nonhydrostatic model based on a new approach. Meteor. Atmos. Phys., 82, 271-285.

Kain, J. S., M. E. Baldwin, P. R. Janish, S. J. Weiss, M. P. Kay, and G. W. Carbin, 2003: Subjective verification of numerical models as a component of a broader interaction between research and operations. Wea. Forecasting, 18, 847-860.

Kessler, E., 1969: On the Distribution and Continuity of Water Substance in Atmospheric Circulation. Amer. Meteor. Soc., 84 pp.

Korolev, A., and G. A. Isaac, 2006: Relative humidity in liquid, mixed-phase, and ice clouds. J. Atmos. Sci., 63, 2865-2880.

Lang, S., W.-K. Tao, R. Cifelli, W. Olson, J. Halverson, S. Rutledge, and J. Simpson, 2007: Improving simulations of convective systems from TRMM LBA: Easterly and westerly regimes. J. Atmos. Sci., 64, 1141-1164.

Lin, Y.-L., R. D. Farley, and H. D. Orville, 1983: Bulk parameterization of the snow field in a cloud model. J. Climate Appl. Meteor., 22, 1065-1092.

Liu, G., 2004: Approximation of single scattering properties of ice and snow particles for high microwave frequencies. J. Atmos. Sci., 61, 2441-2456.

_ 2008a: A database of microwave single-scattering properties for nonspherical ice particles. Bull. Amer. Meteor. Soc., 89, $1563-1570$.
- 2008b: Deriving snow cloud characteristics from CloudSat observations. J. Geophys. Res., 113, D00A09, doi:10.1029/ 2007JD009766.

Lo, K. K., and R. E. J. Passarelli, 1982: The growth of snow in winter storms: An airborne observational study. J. Atmos. Sci., 39, 697-706.

Locatelli, J. D., and P. V. Hobbs, 1974: Fall speeds and masses of solid precipitation particles. J. Geophys. Res., 79, 21852197.

Matsui, T., X. Zeng, W.-K. Tao, H. Masunaga, W. S. Olson, and S. Lang, 2009: Evaluation of long-term cloud-resolving model simulations using satellite radiance observations and multifrequency satellite simulators. J. Atmos. Oceanic Technol., 26, 1261-1274.

Milbrandt, J. A., and M. K. Yau, 2005: A multimoment bulk microphysics parameterization. Part I: Analysis of the role of the spectral shape parameter. J. Atmos. Sci., 62, 3051-3064.

Mlawer, E. J., S. J. Taubman, P. D. Brown, M. J. Iacono, and S. A. Clough, 1997: Radiative transfer for inhomogeneous atmosphere: RRTM, a validated correlated-k model for the long-wave. J. Geophys. Res., 102 (D14), 16 663-16 682.

Morrison, G., G. Thompson, and V. Tatarskii, 2009: Impact of cloud microphysics on the development of trailing stratiform precipitation in a simulated squall line: Comparison of one- and two-moment schemes. Mon. Wea. Rev., 137, 991-1007.

Petersen, W. A., and Coauthors, 2007: NASA GPM/PMM participation in the Canadian CloudSat/CALIPSO validation project C3VP. Physical process studies in snow. Preprints, 33rd Int. Conf. on Radar Meteorology, Cairns, Australia, Amer. Meteor. Soc., 1-7.

Pruppacher, H. R., and J. D. Klett, 1978: Microphysics of Clouds and Precipitation. D. Reidel, $714 \mathrm{pp}$.

Rutledge, S. A., and P. V. Hobbs, 1983: The mesoscale and microscale structure and organization of clouds and precipitation in midlatitude cyclones. Part VII: A model for the seederfeeder process in warm-frontal rainbands. J. Atmos. Sci., 40, $1185-1206$

_ and 1984 : The mesoscale and microscale structure and organization of clouds and precipitation in midlatitude clouds. Part XII: A diagnostic modeling study of precipitation development in narrow cold frontal rainbands. J. Atmos. Sci., 41, 2949-2972.

Ryan, B., 2000: A bulk parameterization of the ice particle size distribution and the optical properties in ice clouds. J. Atmos. Sci., 57, 1436-1451.

Shi, J. J., and Coauthors, 2010: WRF simulations of the 20-22 January 2007 snow events over eastern Canada: Comparison with in situ and satellite observations. J. Appl. Meteor. Climatol., 49, 2246-2266

Stephens, G. L., and Coauthors, 2002: The CloudSat mission and the A-Train. Bull. Amer. Meteor. Soc., 83, 1771-1790.

Tao, W.-K., and Coauthors, 2003: Microphysics, radiation and surface processes in the Goddard Cumulus Ensemble (GCE) model. Meteor. Atmos. Phys., 82, 97-137.

Thompson, G., P. R. Field, R. M. Rasmussen, and W. D. Hall, 2008: Explicit forecasts of winter precipitation using an improved bulk microphysics scheme. Part II: Implementation of a new snow parameterization. Mon. Wea. Rev., 136, 5095-5115.

Twohy, C. H., A. J. Schanot, and W. A. Cooper, 1997: Measurement of condensed water content in liquid and ice clouds using an airborne counterflow virtual impactor. J. Atmos. Oceanic Technol., 14, 197-202. 